\title{
Management of asthma in Australian general practice: care is still not in line with clinical practice guidelines
}

\section{*Christopher Bartona, Judith Proudfoot ${ }^{\mathrm{b}}$, Cheryl Amoroso ${ }^{\mathrm{b}}$, Emmae Ramsay ${ }^{\mathrm{a}}$, Christine Holtona, Tanya Bubnera, Mark Harris ${ }^{b}$, Justin Beilby ${ }^{\mathrm{a}}$}

a Department of General Practice, University of Adelaide, North Terrace, Adelaide, South Australia, 5005, Australia

${ }^{b}$ Centre for Primary Health Care and Equity, University of New South Wales, Sydney, New South Wales, Australia

Received 4th March 2008; revised version received 28th May 2008; accepted 15th July 2008; online 2nd October 2008

\begin{abstract}
Objective and Background: We investigated the quality of primary care asthma management in a sample of Australian general practices.

Methods: 247 general practitioners (GPs) from 97 practices completed a structured interview about management of asthma, diabetes and hypertension/heart disease. A further structured interview with the senior practice principal and practice manager was used to collect information about practice capacity for chronic disease management.

Results: Just under half of GPs (47\%) had access to an asthma register and the majority (76\%) had access to spirometry in their practice. In terms of routine management of asthma, $12 \%$ of GPs reported using spirometry routinely, $13 \%$ routinely reviewed written asthma action plans, $27 \%$ routinely provided education about trigger factors, $30 \%$ routinely reviewed inhaler technique, $24 \%$ routinely assessed asthma severity, and $29 \%$ routinely assessed physical activity. Practice characteristics such as practice size ( $p=1.0)$ and locality (rural/metropolitan) $(p=0.7)$ did not predict quality of asthma management nor did indicators of practice capacity including Business maturity, IT/IM maturity, Multidisciplinary teamwork, and Clinical linkages.

Conclusion: Gaps remain in the provision of evidence-based care for patients with asthma in general practice. Markers of practice capacity measured here were not associated with guideline-based respiratory care within practices.

(c) 2009 General Practice Airways Group. All rights reserved.

C Barton, et al. Prim Care Resp J 2009; 18(2): 100-105.

doi:10.3132/pcrj.2008.00059
\end{abstract}

Keywords asthma, primary health care, practice guidelines, clinical practice, physicians, quality assessment

\section{Introduction}

Asthma affects approximately $12 \%$ of Australian adults and is one of the most common problems managed in general practice. ${ }^{2}$ General practice is ideally placed to manage chronic illnesses like asthma, although current evidence suggests significant variation in the quality of care for major chronic illnesses in primary care settings, ${ }^{3-6}$ and many patients receive less than optimal care. Community surveys of asthma management and outcomes in Australia continue to report high rates of symptoms, yet low rates of use of effective therapies.?

In the UK, Campbell et al reported that the quality of asthma care in the five-year period between 1998 and 2003 improved significantly. ${ }^{8}$ In Australia, mortality from asthma has declined markedly since peaking in 1989, therefore suggesting better quality care, though there are no studies confirming any change in the quality of primary care asthma management during this period. In contrast, there was a 10\% improvement in the quality of care score in the UK which occurred during a period of widespread government and professional initiatives to improve quality of care for asthma in primary care. ${ }^{8}$ These initiatives included provision of widely publicised asthma management guidelines and other primary care interventions. Similar initiatives occurred in Australia during this period, including the dissemination of an Asthma Management Handbook ${ }^{9}$ and government initiatives such as the Asthma 3+ Visit Plan..$^{10}$ It is widely accepted that multifaceted interventions

* Corresponding author: Dr Christopher Barton, Department of General Practice, University of Adelaide, North Terrace, Adelaide, South Australia, 5005 Australia. E-mail: christopher.barton@adelaide.edu.au 
are likely to be more effective at changing clinical practice than simple dissemination of guidelines, but it remains unclear what effect these initiatives have had on the quality of Australian primary care management of respiratory disease.

There have been few studies investigating the quality of chronic illness care in Australian general practice, and we are aware of only one which focusses on the quality of primary care management of asthma; ${ }^{6} 243$ asthma patient records from 17 general practitioners (GPs) were audited over an 8week period and it was found that $73 \%$ of patients had had a recorded asthma review in the past 12 months, 57\% were prescribed regular preventive therapy, and $48 \%$ had been given an asthma action plan. The authors concluded that there was a need for further strategies to be developed to support GPs in improving the quality of care provided to patients with asthma in Australian primary care.

Previously our group has reported significant relationships between the structure and organisation of general practice clinics and the provision of evidence-based clinical care for chronic illness. ${ }^{11}$ Here we report results of a more detailed analysis of data relating to the management of asthma in Australian general practices. The aim of this paper is to describe the management of moderate to severe asthma by a large cohort of Australian GPs, and to determine if the structure and organisation of the practice influences the provision of asthma care that is consistent with the National Asthma Council's asthma management guidelines.

\section{Methods}

The study was granted ethics approval by the University of Adelaide and the University of New South Wales human research ethics committees.

Recruitment of GPs occurred at a practice level. The recruitment of practices was supported by 27 Divisions of General Practice, which are locally-based Commonwealthfunded support organisations for general practice. All practices that were members of the Divisions supporting the study were invited to participate. Recruitment took place between January and September 2004. Expressions of interest to participate were received from 135 practices $(6.5 \%$ of all practices in these divisions), of which 97 practices $(4.7 \%$ of all eligible practices) took part. The 97 General Practice clinics were located across six of the eight states in Australia, with New South Wales $(n=46)$, South Australia $(n=25)$, Victoria ( $n=12)$, Queensland $(n=6)$, Australian Capital Territory $(n=4)$, and Tasmania $(n=4)$ represented. From these practices, 247 GPs completed a structured interview about their management of three common chronic illnesses (asthma, diabetes and hypertension).

\section{Questionnaires}

Prior to the practice visit by researchers, the senior GP principal and practice manager completed a questionnaire to gather demographic information about practice staff and to give descriptive information about the practice.

A new tool, the General Practice Chronic Care Interview (GPCCI) was developed and validated to determine GPs' clinical management of three common chronic illnesses. ${ }^{12}$ The GPCCl is a fully structured, interviewer-administered questionnaire that can be used to determine the quality of clinical care provided to patients with asthma, diabetes, and ischaemic heart disease (IHD)/hypertension. The measurement characteristics, validity and reliability of the instrument have been assessed. ${ }^{12}$ Each section consists of a set of items in four a priori categories - case finding, assessment, patient education, and ongoing management - and is based on evidence-based guidelines. Exploratory Principle Component Factor Analysis was used to identify the key markers of quality chronic illness care at a practice level. Two disease-specific factors (Asthma Assessment and Diabetes Assessment) emerged in addition to three generic chronic illness factors (Care Planning, Risk Factors and Monitoring). The asthmaspecific factor comprised five items indicating 'asthma assessment' (assessed severity, performed spirometry, reviewed inhaler use, educated about trigger factors, assessed physical activity). A total score was obtained for this scale by summating the number of GPs who reported completing each clinical management item on more than $80 \%$ of patients with moderate to severe asthma seen in the past 12 months, and averaging this across the practice to provide a practice score. This total score is indicative of how closely practitioners provide care that is in line with the 2002 National Asthma Council (NAC) Asthma Management Handbook guidelines. ${ }^{13}$ The maximum possible score was 5.0.

\section{Data analysis}

Descriptive data were summarised using frequency counts, means and standard deviations. Data arising from the GPCCI were summarised using medians, the 25th and 75th percentile, and then analysed using median regression since the data were not normally distributed and no transformations of the data were appropriate. Univariate median regression analyses were performed on all potential predictors and confounders, to determine the impact of practice and GP characteristics on the provision of respiratory care and to identify predictors of guideline-based asthma assessment. The final multivariate model included the variables that had a P-value of less than 0.2 in the univariate analyses. Significance for the final model was assessed at the $5 \%$ level.

\section{Results}

Demographic details of participating GPs can be found in Table 1. Frequency counts for GPs' self-reported asthma management actions are reported in Table 2. Most GPs 
Table 1. Characteristics and details of participating practices

\section{N (\%)}

\begin{tabular}{lc}
\hline Size of practice & \\
$1 \mathrm{GP}$ & $25(25.8 \%)$ \\
$2-3 \mathrm{GPs}$ & $32(33 \%)$ \\
4 or more GPs & $40(41.2 \%)$ \\
Total practices & 97 \\
\hline
\end{tabular}

$\begin{array}{lc}\begin{array}{l}\text { Location of practice } \\ \text { State/Territory }\end{array} \\ \text { New South Wales } & 46(47.4 \%) \\ \text { South Australia } & 25(25.8 \%) \\ \text { Victoria } & 12(12.4 \%) \\ \text { Queensland } & 6(6.2 \%) \\ \text { Tasmania } & 4(4.1 \%) \\ \text { Australian Capital Territory } & 4(4.1 \%)\end{array}$

\section{RRMA}

$\begin{array}{lc}\text { Capital City/Metropolitan } & 63(65 \%) \\ \text { Large Rural } & 4(4.1 \%) \\ \text { Small Rural } & 7(7.2 \%) \\ \text { Other Rural / Remote } & 23(23.7 \%)\end{array}$

Practice has a nurse

$\begin{array}{ll}\text { Yes } & 57(59 \%) \\ \text { No } & 40(41 \%)\end{array}$

reported that there was a spirometer in the practice $(74.9 \%)$ and that they used patient-held records for asthma (56.7\%). Just under half reported that their practice had a register of patients with asthma (47.4\%) (Table 2). However, far fewer GPs used these tools routinely for asthma management (defined as use on more than $80 \%$ of patients with moderate to severe asthma seen in past 12 months) and fewer than one in three GPs routinely assessed asthma severity, reviewed inhaler use, provided education on prevention of trigger factors, or provided a written asthma action plan (Table 2). Likewise, less than a third of GPs routinely asked patients with asthma about behavioural risk factors such as smoking, nutrition, alcohol and physical activity (Table 2).

The median practice score for asthma assessment was 1.0 (maximum possible score 5$)(\mathrm{IQR}=2.0)$. Practice characteristics such as practice size (<4 GPs vs $4+$ GPs) and locality (urban vs rural) did not predict GPCCI asthma score nor did indicators of practice capacity including multidisciplinary team work, business and financial management, IT/IM maturity, or clinical linkages (Table 3). There was weak evidence that the practice capacity subscale "computer use for clinical records" predicted respiratory assessment scores (Table 3).
Table 2. Resources and asthma management behaviours of General Practitioners reported on the Clinical Care Interview.

\begin{tabular}{|c|c|}
\hline Item & *N (\%) \\
\hline \multicolumn{2}{|c|}{ Resources to manage asthma } \\
\hline \multicolumn{2}{|c|}{ Spirometer in Practice } \\
\hline Yes & $185(74.9 \%)$ \\
\hline No & $57(23.1 \%)$ \\
\hline \multicolumn{2}{|c|}{ Clinical care guidelines for asthma } \\
\hline Yes & $107(43.3 \%)$ \\
\hline No & $135(54.7 \%)$ \\
\hline \multicolumn{2}{|c|}{ Patient held records } \\
\hline Yes & $135(56.7 \%)$ \\
\hline No & $107(41.3 \%)$ \\
\hline \multicolumn{2}{|c|}{ Asthma Register } \\
\hline Yes & $117(47.4 \%)$ \\
\hline No & $125(50.6 \%)$ \\
\hline
\end{tabular}

Asthma management

(GP provided item to more than $80 \%$ of patients seen with moderate to severe asthma in last 12 months

$\begin{array}{ll}{ }^{+} \text {Assessed for asthma severity } & 57(23.1 \%) \\ { }^{+} \text {Had a spirometry test } & 29(11.7 \%) \\ { }^{+} \text {Had inhaler use reviewed } & 74(30.0 \%) \\ { }^{+} \text {Received education on prevention } & \\ \text { of trigger factors } & 65(26.3 \%) \\ \text { Provided with a written action plan } & 32(13.0 \%) \\ \text { Asthma register used to monitor cycle of care } & 43(17.4 \%)\end{array}$

Proportion of patients assessed for behavioural risk factors in last 6 months

Assessed smoking

$118(50.2 \%)$

Assessed nutrition

$17(6.9 \%)$

Assessed alcohol consumption

$28(11.3 \%)$

${ }^{\dagger}$ Assessed physical activity

$71(28.7 \%)$

†'tem contributing to Respiratory Assessment total score

*Total number of GPs $=247$

$\%$ does not always equal 100 due to missing data.

\section{Discussion}

There are two principal findings arising from this study. First, most GPs in this study were not managing asthma in line with recommendations from the NAC Asthma Management Guidelines. Secondly, markers of practice capacity (Team working, IM/IT maturity, Business and Finance, Clinical linkages) were not associated with guideline-based respiratory care at a practice level. There was weak evidence to suggest that the subscale score "computer use for clinical records" predicted respiratory assessment scores. However, due to the number of analyses performed, and given that this was an unexpected observation, this finding needs to be investigated further before 
Table 3. Results of a Median Regression Analysis to evaluate the relationship between indicators of practice capacity for chronic disease management and practice level score on the General Practice Chronic Care Interview Asthma Assessment sub scale.
T-Value
P-value
$95 \% \mathrm{Cl}$

$\begin{array}{lccc}\text { Business and Financial Management } & & 1.0 & -0.2 \text { to } 0.2 \\ \text { Practice Development } & 0.00 & 1.0 & -0.3 \text { to } 0.3 \\ \text { HR/Staff development } & 0.00 & 0.61 & -0.2 \text { to } 1.4 \\ \text { SWOT/Market position } & 0.52 & 1.0 & -0.3 \text { to } 0.3 \\ \text { Financial planning } & 0.00 & 1.0 & -0.1 \text { to } 0.1 \\ \text { Business and Finance Total } & 0.00 & \end{array}$

\begin{tabular}{|c|c|c|c|}
\hline \multicolumn{4}{|l|}{ Multidisciplinary Team Working } \\
\hline Non GP Clinical functions & 0.00 & 1.0 & -0.1 to 0.1 \\
\hline Admin functions & 0.00 & 1.0 & -0.3 to 0.3 \\
\hline Practice management functions & 0.00 & 1.0 & -0.2 to 0.2 \\
\hline Communication & 0.00 & 1.0 & -0.6 to 0.6 \\
\hline Team working Total & 0.00 & 1.0 & -0.7 to 0.7 \\
\hline
\end{tabular}

\begin{tabular}{|c|c|c|c|}
\hline \multicolumn{4}{|l|}{ IM/IT maturity } \\
\hline Computer use for Clinical Records & -2.4 & *0.017 & -0.3 to -0.03 \\
\hline Advanced IMIT & 0.00 & 1.0 & -0.4 to 0.4 \\
\hline Computer use for Administration & 0.00 & 1.0 & -0.2 to 0.2 \\
\hline Support for Clinical Care & 0.00 & 1.0 & -0.3 to 0.3 \\
\hline IMIT Maturity Total & 0.00 & 1.0 & -0.08 to 0.08 \\
\hline \multicolumn{4}{|l|}{ Clinical linkages } \\
\hline Referral and Advice & 0.00 & 1.0 & -0.6 to 0.6 \\
\hline Shared Care and Care Planning & 0.00 & 1.0 & -0.2 to 0.2 \\
\hline Community Access and Awareness & & 1.0 & -0.2 to 0.2 \\
\hline Clinical Linkages Total & 0.68 & 0.5 & -0.06 to 0.1 \\
\hline
\end{tabular}

${ }^{*} \mathrm{p}<0.05$

a conclusion can be made about the value of computers for clinical support and provision of evidence-based care for asthma.

The primary aim of our study was to determine if existing practice capacity was associated with the quality of care for patients with asthma in primary care. Practice capacity refers to the ability of a general practice to provide efficient, effective, sustainable care for patients with major chronic illness who attend the practice. The requirements for optimal practice capacity vary according to location, characteristics of the practice, and the wider patient population served by the practice. That we did not identify associations between practice capacity and the quality of primary respiratory care, suggests that other GP-related factors may be more important determinants of quality of clinical care for patients with asthma; or alternatively, indicators of practice capacity that were not assessed may be more relevant determinants of the quality of respiratory care.

Quality of respiratory care was assessed against recommendations in the 2002 NAC Asthma Management Handbook. ${ }^{13}$ During the past decade, a range of programs and incentives to support GPs in improving the management of asthma in Australia have been introduced by government and professional bodies with mixed success. Guidelines for asthma management were developed in Australia ${ }^{14}$ in an attempt to improve and standardise care for asthma in the community in the 1990's. The Australian guidelines are based on a six-step asthma management plan, are disseminated by the NAC in their Asthma Management Handbook (2002), ${ }^{13}$ and have recently been revised and updated. ${ }^{15}$ These guidelines have been disseminated widely in primary care throughout Australia and are accepted by the scientific and medical community as representing a good, evidence-based guide to the management of asthma. Our findings are consistent with the findings from other international studies that many GPs are not managing asthma in line with clinical practice guidelines. ${ }^{8,16}$ Unfortunately, the findings from these 
studies and our study cannot tell us why GP care is not more consistent with guidelines, how to increase compliance with guideline recommendations, or indeed, whether increased compliance would improve health outcomes for patients. It is accepted that many patients do not manage their asthma as a chronic illness, preferring to treat it episodically and accept a level of morbidity accordingly; ${ }^{17}$ likewise, a large proportion of GPs in this study also seemingly manage asthma in a way that is not consistent with evidence-based guidelines. Whether this style of care is associated with any negative health outcomes for patients needs to be investigated.

There is a need to explore further why a gap still exists in the provision of evidence-based care for asthma in primary care, and to identify how GPs and practices can be supported to encourage adoption of evidence-based practices. Since the completion of the current study, a number of Australian initiatives have been revised - such as the Asthma Cycle of Care program which supersedes Asthma 3+, revised Medicare items, and an updated asthma management handbook. The impact of these updated initiatives will need to be evaluated carefully to determine if the quality of care is improved and if there are knock-on effects to patients in terms of improved self-management of asthma and better health.

\section{Limitations of this study}

No specific difficulties were encountered during the study which could impact on the findings. However, there are some general limitations. The GPs who took part in the study were required to return an expression of interest form. These doctors may differ from other GPs in that they are more likely to be interested in chronic illness care and therefore not representative of the GP population as a whole - so the findings should be generalised with caution. Also, this was a secondary analysis of data from a larger cross-sectional study investigating the relationships between practice capacity and chronic disease management. Since it is a cross-sectional study the findings do not tell us how we can improve GPs' adherence to asthma guidelines and encourage better quality respiratory care. Additionally, the data were based on selfreport from GPs regarding clinical practices and may overestimate compliance with guideline recommendations. These findings require replication in a study designed specifically to measure respiratory management capacity. If such a study is to occur, further development work on the GPCCI instrument would be useful; this instrument performed poorly on internal consistency and should be updated to reflect the latest clinical practice guidelines for asthma.

Finally, our assessments of quality were based on the 2002 NAC asthma management handbook which has since been updated. ${ }^{15}$ Other guidelines (e.g. GINA) could have been used as the marker of quality and may have yielded different results.

\section{Summary}

- Most GPs in this study were not managing asthma in line with recommendations from the 2002 Australian National Asthma Council Asthma Management Guidelines.

- The majority of GPs (but not all) in the study had the tools and resources to manage asthma in line with evidencebased guidelines.

- Markers of practice capacity (Team working, IM/IT maturity, Business and Finance, Clinical linkages) assessed in this study were not associated with guideline-based respiratory care at a practice level.

\section{Conclusions}

These results indicate that many GPs in Australia are not managing moderate to severe asthma in line with evidencebased clinical practice guidelines, despite most GPs having the resources to do so. Questions that need to be resolved are whether these findings are indicative of limitations in the dissemination of the 2002 asthma management guidelines into general practice, and whether there is a more fundamental problem with the suitability of these guidelines for use in primary care or as a measure of quality of care.

\section{Conflict of interest declaration}

There are no conflicts of interest to declare.

\section{References}

1. Australian Centre for Asthma Monitoring. Asthma in Australia 2003. AlHW Asthma Series 1. AlHW Cat. no. ACM1. Canberra: AlHW; 2003.

2. Beilby J, Furler J. General practitioner services in Australia. In: Daniel J, Harris M, Humphreys J, Kalucy L, Maclsaac P, Mott K et al. (eds). General Practice in Australia 2004. 3 ed. Fyshwick: National Capital Printing, 2004;129-214.

3. Seddon ME, Marshall MN, Cambell SM, Roland MO. Systematic review of studies of quality of clinical care in general practice in the UK, Australia, and New Zealand. Quality in Health Care 2001;10:152-8. http://dx.doi.org/10.1136/ qhc.0100152.

4. Briganti EM, Shaw JS, Chadban SJ et al. Untreated hypertension among Australian adults: the 1999-2000 Australian Diabetes, Obesity and Lifestyle Study (AusDiab). Med J Aust 2003;179(3):135-9.

5. Senes S, Britt H. A general practice view of cardiovascular disease and diabetes in Australia. Canberra: AIHW \& USyd; 2001. Report No.: 18

6. Collins S, Beilby J, Fardy J, Brurgess T, Johns R, Booth B. The national asthma audit: Bridging the gap between guidelines and practice. Australian Family Physician 1998;27(10):907-13.

7. Marks G, Abramson M, Jenkins C, Kenny P, Mellis C, Ruffin R. Asthma management and outcomes in Australia: a nation-wide telephone interview survey. Respirology 2007;12(2):212-19. http://dx.doi.org/10.1111/j.14401843.2006.01010.x

8. Campbell SM, Roland MO, Middleton E, David R. Improvements in quality of clinical care in English general practice 1998-2003: Iongitudinal observation study. BMJ 2005;331:1121-6. http://dx.doi.org/10.1136/bmj.38632.611123.AE

9. Asthma Management Handbook. Melbourne: National Asthma Campaign Ltd.; 1998. 
10. Glasgow N, Ponsonby A, Yates R, Beilby J, Dugdale P. Proactive asthma care in childhood: general practice based randomised controlled trial. BMJ 2003; 327(7416):659. http://dx.doi.org/10.1136/bmj.327.7416.659

11. The capacity of Australian general practices for chronic disease prevention and management. Record of proceedings of the National Forum. Sydney: Centre for General Practice Integration Studies (CGPIS) and Primary Health Care Research and Information Service, Flinders University (PHCRIS); 2005.

12. Proudfoot J, Jayasinghe $U$, Infante $F$ et al. Quality of chronic disease care in general practice: the development and validation of a provider interview tool. BMC Family Practice 2007;8:21. http://dx.doi.org/10.1186/1471-2296-8-21

13. Asthma Management Handbook. Melbourne: National Asthma Council
Australia; 2002

14. Woolcock A, Rubinfeld AR, Seale JP et al. Thoracic society of Australia and New Zealand. Asthma management plan, 1989. Med J Aust 1989;151(11-12):650-3.

15. Asthma Management Handbook. Melbourne: National Asthma Council Australia; 2006

16. Tsuyuki RT, Sin DD, Sharpe HM, Cowie RL, Nilsson C, Man SF. Management of asthma among community based primary care physicians. Journal of Asthma 2005;42(3):163-7. http://dx.doi.org/10.1081/JAS-200054615

17. Horne R. Compliance, Adherence, and Concordance. Chest 2006;130 (Supplement 1):65S-72S.

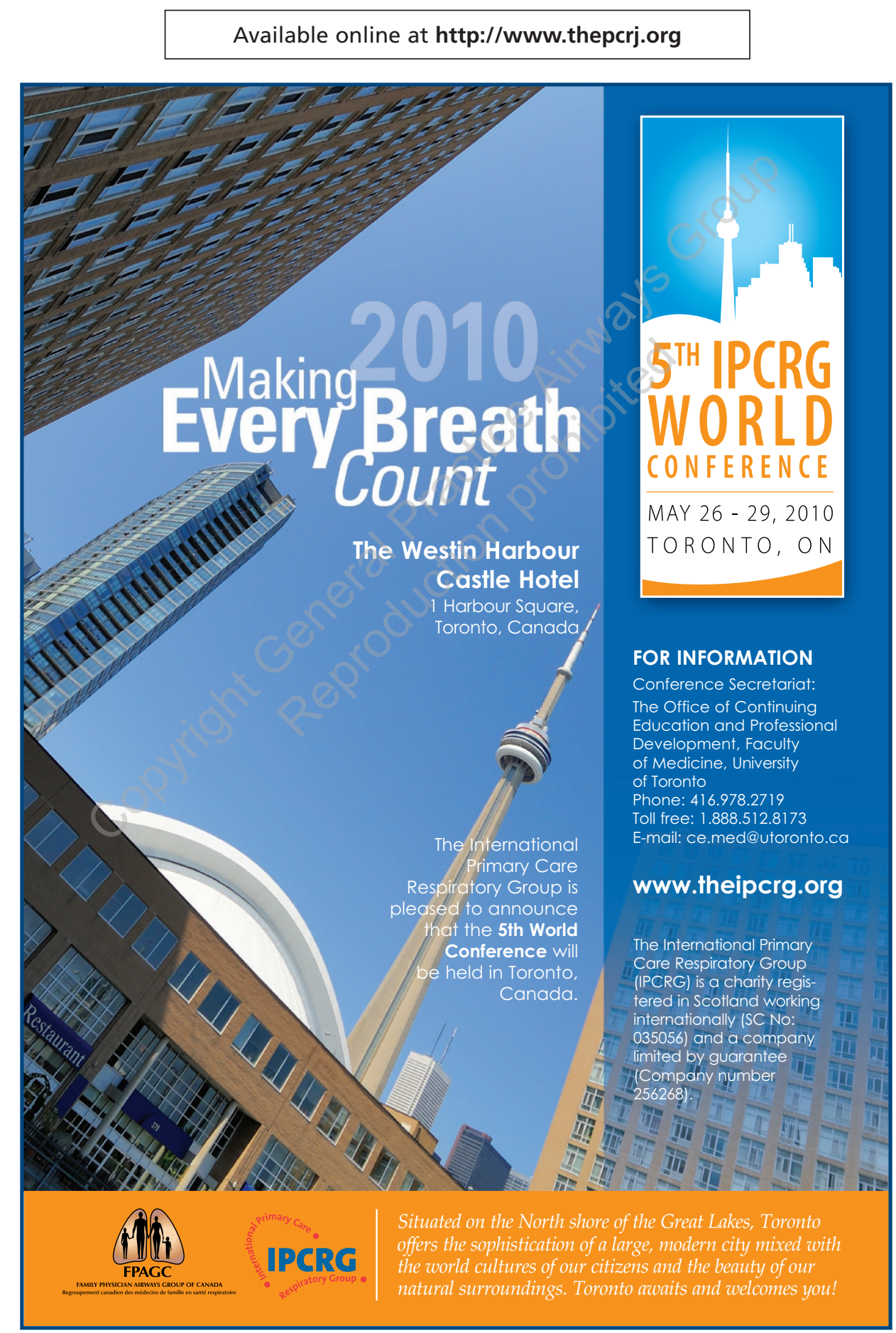

